\title{
Study of Cholesterol Levels in Ascitic Fluid to Differentiate Malignant from Non-Malignant Effusion
}

\author{
Vinay Sharmaํ, Rachna Sharma², Pooja Arora ${ }^{3}$, Neetu Goyal'4, Sushil Sharma ${ }^{5}$
}

\begin{abstract}
${ }^{1}$ Department of Pathology, Venkateshwara Institute of Medical Sciences, Gajraula, Uttar Pradesh, India. ${ }^{2}$ Department of Pathology, SMMH Medical College, Saharanpur, Uttar Pradesh, India. ${ }^{3}$ Department of Pathology, SMMH Medical College, Saharanpur, Uttar Pradesh, India. ${ }^{4}$ Department of Pathology, SMMH Medical College, Saharanpur, Uttar Pradesh, India.

${ }^{5}$ Department of Physiology, Venkateshwara Institute of Medical Sciences, Gajraula, Uttar Pradesh, India.
\end{abstract}

\section{ABSTRACT}

\section{BACKGROUND}

Collection of more than normal quantity fluid in a serous cavity is called effusion. It is classified as per location i.e. pericardial, pleural and peritoneal. Fluid collection in abdominal cavity is called ascites. Effusions are of two types - (1) Transudate (2) Exudate. Transudate develops as a result of physiological disturbances of circulation usually a rise in venous pressure or decrease in oncotic pressure, while exudate forms as a result of increased capillary permeability which is usually due to inflammation. Transudates usually have low specific gravity due to low protein content whereas exudates have high specific gravity due to high protein content. Transudates are usually associated with cardiac-, hepatic- or renal-disease. While exudates are caused by inflammatory conditions like tuberculosis and malignancies of pelvic and abdominal organs. Recently fibronectin and cholesterol levels of peritoneal fluid have been found to differentiate between ascites of different aetiologies. The estimation of fibronectin levels in fluid is sensitive but complicated. So, in this study we have taken the value of cholesterol for the aetiologic diagnosis of ascites as a simple procedure.

\section{METHODS}

The present descriptive study of 100 cases of ascites was conducted over a period of 12 months i.e. January. 2019 to January 2020. Various fluids were collected from OPD and IPD of Medical and Surgery units.

\section{RESULTS}

In the present study, $84 \%$ of the cases were transudates while exudates accounted for $16 \%$ of cases. Cirrhosis (65\%) was the commonest cause among transudates. Other causes included congestive cardiac failure (09\%), nephrotic syndrome (06\%), $\&$ anaemias $(04 \%)$. Exudative ascites was caused by tuberculosis in $10 \%$ cases $\&$ malignancy in $06 \%$ cases. Cholesterol level of $>70 \mathrm{mg} / \mathrm{dL}$ was found in $82 \%$ of malignant ascites. So, it was concluded that ascitic fluid cholesterol levels were significantly greater in malignant cases in comparison to ascites caused by non malignant aetiologies. Inference - Cholesterol concentration in ascitic fluid helps to differentiate ascites in malignancy, from non - malignant ascites.

\section{CONCLUSIONS}

Cholesterol estimation in ascitic fluid is a better parameter to differentiate malignant ascites from non - malignant ascites.

\section{KEY WORDS}

Cholesterol, Ascites, Transudate, Exudate

\author{
Corresponding Author: \\ Dr. Rachna Sharma, \\ W/o. Dr. Vinay Sharma, \\ \#185, Pawan Vihar, \\ Jain College Road, $4^{\text {th }}$ Lane, \\ Ashram Riti Vidhyalam, \\ Saharanpur - 247001, \\ Uttar Pradesh, India. \\ E-mail: rachnasharmasre@gmail.com
}

DOI: $10.14260 /$ jemds/2020/414

Financial or Other Competing Interests: None.

How to Cite This Article:

Sharma V, Sharma R, Arora P, et al. Study of cholesterol levels in ascitic fluid to differentiate malignant from nonmalignant effusion. J. Evolution Med. Dent. Sci. 2020;9(26):1903-1907, DOI: $10.14260 /$ jemds/2020/414

Submission 18-03-2020,

Peer Review 30-05-2020

Acceptance 06-06-2020,

Published 29-06-2020.

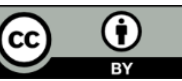




\section{BACKGROUND}

There are serous cavities around delicate organs for their protection. Normally these cavities are either collapsed or contain very little lubricant fluid between the two layers i.e. the parietal and visceral layers. The visceral \& parietal layer surface of each cavity are lined by membrane i.e. mesothelium, supported by connective tissue \& an appropriate vascular \& nervous apparatus.

In the absence of disease, the parietal and visceral layers of the mesothelium are separated by a thin layer of lubricating fluid that facilitates the movements of the two membranes against each other. Therefore the cavities are no true cavities but virtual cavities. The presence of gases and fluids will change them into true cavities. The viscera are external to the serous cavity \& invaginate the visceral mesothelium. Thus the serous fluid normally lubricates \& supports the visceral movement.

Whenever there is certain physical disturbance like increase in venous pressure or lowering of oncotic pressure or increase in the permeability of capillary membrane, the fluid starts accumulating in the potential spaces i.e. pleural, peritoneal or pericardial cavities. Slowly it starts exceeding the amount of fluid that is normally present in the cavity.

The two mechanisms that are involved in the development of effusions are

1. Increased venous pressure or drop in oncotic pressure in case of transudative effusion.

2. Increase in the permeability of capillary membrane in case of development of exudative effusion.

As there is Increase in the permeability of capillary membrane it allows more \& more proteins \& cells to seep into the fluids and hence there are higher protein levels and higher cell counts in the exudative fluids than the transudative ones. When exudates are due to infections microorganisms can be present in the fluids. In case of trauma foreign bodies may be identified in the fluids. When excessive fluid is collected in peritoneal cavity it is called ascites. There can be mild to massive increase of fluid in the peritoneal cavity due to liver, heart, inflammatory and malignant conditions.

The customary methods of investigation of causes of effusions are cytological examination of the fluid \& biopsy of the peritoneum supplemented by biochemical and bacteriological examination. The previous approach in differential diagnosis was the protein concentration in the ascitic fluid \& the cut off levels was $2.5 \mathrm{gm} / \mathrm{dL}$ above that was considered as exudates and it transudate. Certain other parameters like LDH \& $\mathrm{PH}$ of ascitic fluid have been tried but of no use. A number of biochemical markers like hCG, CEA and CA - 125 are often measured in certain conditions the value of these procedures is still being debated. They sometime supplement but rarely replace the standard fluid examination.

Now a days, fibronectin and cholesterol levels of peritoneal fluid have been found to differentiate between ascites of different aetiologies. The estimation of fibronectin levels in fluid is sensitive but complicated. So, in this study we have taken the value of cholesterol for the aetiologic diagnosis of ascites as a simple procedure.

\section{Objectives}

1. To compare clinical diagnosis with biochemical and cytological findings.

2. To evaluate cholesterol concentration in ascitic fluid as a better diagnostic parameter.

\section{METHODS}

This is a descriptive study. One hundred patients with ascites attending the medical and surgical units, VIMS, Amroha district, for a span of twelve months from January 2019 January 2020 were selected for the study. The study was approved by Ethics Committee and informed consent was obtained.

\section{Collection of Fluids}

1. Aseptic precautions taken.

2. Samples collected in two vials- one in EDTA for cytology $\&$ another one in plain vial for biochemistry.

3. Samples were processed as soon as possible.

\section{Case Allocation}

In present study 100 cases of ascites were taken for a span of 12 months i.e. January 2019 to January 2020. Various fluids were collected from OPD's and IPD's of Medical and Surgery units.

\section{Considerations for Inclusion of Samples}

a. In cases of cirrhosis clinical history, Ultrasound and increased AST, ALT values were considered.

b. For patients of nephrotic syndrome facial puffiness, pedal oedema. albuminuria raised urea/creatinine levels were taken as criteria.

c. for Congestive Cardiac Failure Clinical findings along with ECG findings were included

d. For anaemia clinical presentation, $\mathrm{Hb} \%$ and low serum protein levels were taken into account.

e. For tuberculosis raised ESR, H/O ATT drugs, X Ray (chest), ZN staining for acid fast bacilli \& raised values of fluid proteins were considered as criteria.

f. For malignancy clinical history, presence of neoplastic cells in fluid/ FNAC/ histopathology were considered.

g. Fluids were examined for biochemistry \& cytology.

\section{For Cholesterol Estimation}

Cholesterol concentration estimation was done by using Autopak cholesterol kits.

\section{For Cytology}

Total leucocyte count was done using readymade diluting fluid. Differential count was done using Leishman's stain. Cytology smears were made by centrifuging ascitic fluid for 05 minutes at $2000 \mathrm{rpm}$. Smears made from the sediment \& stained by H\&E stain and observed under microscope for morphology. 


\section{Technique}

Cholesterol concentration was estimated with Cholesterol kits from Ames (Autopak).

\section{Principle}

Free cholesterol \& fatty acids are formed by hydrolysis of cholesterol esters by cholesterol ester hydrolase. There is pre - existing cholesterol which along with the cholesterol produced by the above reaction is converted into cholestenone \& hydrogen peroxide because of oxidation by cholesterol oxidase. $\mathrm{H}_{2} \mathrm{O}_{2}$ In the presence of peroxidase oxidises the chromogen to red colour complex to be read at $520 \mathrm{~nm}$. This colour is constant for two hours unless kept in sun light.

\section{Procedure for Cholesterol Estimation}

- 1 tube was labelled as blank (B).

- 1 more tube was labelled as standard (S).

- $\quad$ Rest of the tubes were labelled as test (T) \& numbered according to the number of samples of ascitic fluid.

- In each tube $1 \mathrm{ml}$ of cholesterol reagent was poured after bringing the reagent to room temperature.

- In the tube B add 10 microlitre of distilled water, in the tube S add 10 microlitre of Cholesterol standard, In the tubes.

Labelled as $\mathrm{T}$ add 10 microlitre of supernatant from respective fluid samples. Keep all the tubes at $37^{*} \mathrm{C}$ for 10 minutes. Take their respective readings after calibration with standard. Note down all the readings.

\section{Procedure for H \& E Staining}

1. Fix in Ether alcohol (1:1) for 25 - 30 minutes.

2. Stain with Haematoxylin for 3 - 4 minutes.

3. Differentiated with Acid alcohol (1\%).

4. For Hydration - Keep for 4 - 6 mins. in running tap water.

5. Counter stain for $1-2$ mins, with eosin.

6. To remove excess of eosin give two dips in tap water.

7. Blot the slide 3 - 4 times.

8. Keep for one \& a half - two mins in $100 \%$ alcohol for dehydration.

9. Blot the slide.

10. Dip in clearing agent (Xylene) - $4-5$ times.

11. Blot again

12. Mount in DPX.

\section{Statistical Analysis}

The data was formulated in MS - Excel spread sheet, data summarised, frequencies \& means calculated, Fisher Exact test for significance was applied and the same is analysed by Epi Info 7 Software.

\section{RESULTS}

The common cause of ascites in $3^{\text {rd }}$ and $4^{\text {th }}$ decade were cirrhosis and tuberculosis. In $4^{\text {th }}$ and $5^{\text {th }}$ decade it was malignancy. In males, cirrhosis of liver, nephrotic syndrome \& malignancy were common reasons for ascites while tuberculosis, congestive cardiac failure and anaemia were common in females.

\begin{tabular}{|cccc|}
\hline Sl. No. & Aetiology & Cases (Number) & Percentage \\
A & Cirrhosis of Liver & 65 & 65 \\
B & Peritoneal Tuberculosis & 10 & 10 \\
C & Congestive Cardiac Failure & 09 & 09 \\
D & Nephrotic syndrome & 06 & 06 \\
E & Anaemia hypoproteinaemia & 04 & 04 \\
G & Ascites in Malignancy & 06 & 06 \\
\hline \multicolumn{4}{c}{ Table 1. Aetiological Distribution of 100 Cases of Ascites } \\
\hline
\end{tabular}

\begin{tabular}{|cccccccc|}
\hline & & & & \\
\end{tabular}

\begin{tabular}{|c|c|c|c|c|c|c|}
\hline 冚 & 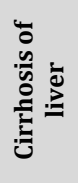 & 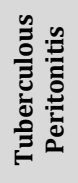 & 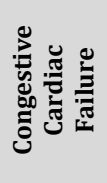 & 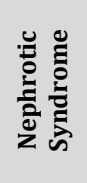 & 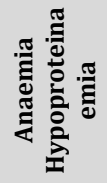 & 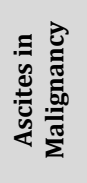 \\
\hline Yellow & $86.2 \%$ & - & $100 \%$ & $100 \%$ & $100 \%$ & - \\
\hline $\begin{array}{l}\text { Amber } \\
\text { coloured }\end{array}$ & $12.3 \%$ & - & - & - & - & - \\
\hline Turbid & $1.5 \%$ & $90 \%$ & - & - & - & 66.7 \\
\hline Haemorrhagic & - & $10 \%$ & - & - & - & 33.3 \\
\hline \multicolumn{7}{|c|}{ Table 3. Gross Appearance of Ascitic Fluid in 100 Cases } \\
\hline \multicolumn{7}{|c|}{$\begin{array}{l}\text { In tuberculous peritonitis and in Malignancy fluid was mostly turbid while fluid was } \\
\text { mostly clear yellow/amber coloured In the cases of cirrhosis of liver, congestive } \\
\text { cardiac failure, nephrotic syndrome and anaemia. In tuberculosis ( } 10 \% \text { cases) and } \\
\text { ascites in Malignancy ( } 33.3 \% \text { cases) haemorrhagic fluid was found. }\end{array}$} \\
\hline
\end{tabular}

\begin{tabular}{|c|c|c|c|}
\hline Aetiology & $\begin{array}{c}\text { Cell Count Less } \\
\text { than } 100 \text { Per } \\
\text { Cubic mm }\end{array}$ & $\begin{array}{l}\text { Cell Count } 100 \\
\text { to } 500 \text { Per } \\
\text { Cubic mm }\end{array}$ & $\begin{array}{c}\text { Cell Count } \\
\text { more than } \\
500 \text { per } \\
\text { Cubic mm }\end{array}$ \\
\hline Cirrhosis of liver & $60(92.3 \%)$ & $04(6.2 \%)$ & $1(1.5 \%)$ \\
\hline Tubercul & & $07(70$ & NA \\
\hline Congestiv & & & NA \\
\hline Nephrotic syndrome & 061 & NA & NA \\
\hline Anaemia hypoproteinaemia & $04(100 \%)$ & NA & NA \\
\hline Ascites in Malignancy & $04(66.6 \%)$ & $02(33.4 \%)$ & NA \\
\hline \multicolumn{4}{|c|}{ Table 4. Nucleated Cells in Ascitic Fluid of Various Aetiologies (\%) } \\
\hline \multicolumn{4}{|c|}{$\begin{array}{l}\text { In tuberculosis ( } 70 \% \text { cases), in Malignancy ( } 33.4 \% \text { cases) and in cirrhosis ( } 7.7 \% \\
\text { cases) nucleated cell count more than } 100 \text { per cubic mm was found in ascitic fluid }\end{array}$} \\
\hline
\end{tabular}




\begin{tabular}{|cccc|}
\hline Aetiology & $\begin{array}{c}\text { Ascitic fluid } \\
\text { Cholesterol } \\
\text { Concentration } \\
\text { (mg/dL) }\end{array}$ & $\begin{array}{c}\text { Mean } \\
\text { Cholesterol } \\
\text { Concentration } \\
\text { (mg/dL) }\end{array}$ & \\
Cirrhosis of liver & $6-38$ & $21 \pm 5.96$ & \\
Tuberculous peritonitis & $16-40$ & $26 \pm 7.34$ & p value \\
Congestive cardiac failure & $7-25$ & $16 \pm 6.72$ & $<0.0001$ \\
Nephrotic - syndrome & $8-21$ & $18 \pm 11.18$ & highly \\
Anaemia - hypo proteinemia & $8-26$ & $18 \pm 9.07$ & significant \\
Ascites in Malignancy & $48-92$ & $61 \pm 17.41$ & \\
\hline \multicolumn{4}{|c|}{ Table 5. Mean Values of Cholesterol Concentration } \\
in Ascites of Different Aetiologies & \\
\hline Fisher Exact Test was applied In the above table, and p value was less than 0.0001 \\
that is considered as very significant
\end{tabular}

\begin{tabular}{|cc|}
\hline \multicolumn{2}{|c|}{$\begin{array}{c}\text { Cholesterol Concentration } \\
\text { Publishers }\end{array}$} \\
Mean Ascitic fluid cholesterol (mg/dL) \\
Albillos A. et al 1990 & $33 \pm 21$ \\
Garg R. et al 1993 & $29.93 \pm 9.21$ \\
Colli A. et al 1993 & $30.1 \pm 3.3$ \\
Present study & $21 \pm 5.96$ \\
Comparison of Mean Cholesterol levels in Ascitic Fluid \\
Publishers & Mean Ascitic fluid cholesterol (mg/dL) \\
Albillos A. et al 1990 & $95 \pm 42$ \\
Garg R. et al 1993 & $89.52 \pm 49$ \\
Present study & $61.00 \pm 17.41$ \\
\hline Table 6. Comparison of Cholesterol Concentration \& Mean Cholesterol \\
Levels in Ascitic Fluid between Other Studies and Our Study \\
\hline
\end{tabular}

In all the cases of non - malignant ascites total cholesterol values were less than $40 \mathrm{mg} / \mathrm{dL}$; while in malignant ascites it was more than $48 \mathrm{mg} / \mathrm{dL}$.

Statistically there is significant difference between ascitic fluid cholesterol levels in non - malignant (i.e. liver disease or tuberculosis) and ascites in malignancy. Thus, ascitic fluid total cholesterol concentration is helpful in drawing a line between non - malignant and ascites in malignancy.

In our study values of cholesterol in ascitic fluid was found to be greater in cases positive for malignant cells on cytology than those which were negative for malignant cells. So in doubtful smears ascitic fluid cholesterol level can guide us whether the smear is truly positive for malignant cells or not.

\section{DISCUSSION}

The clinical picture in most of the cases of ascites is usually not clear. Therefore, we need to investigate ascitic fluid for its aetiological classification which itself is quite often cumbersome. Transudative form is seen in various liver pathologies, CCF, anaemias and diseases of renal origin. In tuberculous peritonitis and malignancy exudate is common.

In our study we found most of our cases (51\%) in age group 30 to 40 yrs., which matches with study of Jain S.C. et al 1966.(1) i.e. $(66 \%)$.

In the present study $64 \%$ patients were male and $36 \%$ were female that coincides with Nath et al 1966(2) in which male and female percentage was $70 \%$ and $30 \%$ respectively. Findings of Nath et al 1966(2) (58.6\%) and those of Mehrotra M. P. and Mangal R. P. 1964(3) (50\%) cases of ascites were seen in cirrhosis that are comparable with our observation (i.e. $65 \%$ cases of ascites caused by cirrhosis). Now a days because of more social campaigning, early detection \& treatment of tuberculosis we found only $10 \%$ cases of tuberculous ascites which is much less as compared to study by Jain S.C. et al 1966(1) (42\%) and Mehrotra M.P. and R.P. Mangal 1964(3) (30\%).
Finding of Mehrotra M. P. and Mangal R.P. 1964(3) (6\%) correlates with our observation i.e. 09\% cases of congestive cardiac failure as a cause of ascites. For unexplained reason CCF was found to be the cause of ascites in a study by Sikka et al 1967.(4) (21.7\%). Similar to the finding of Tito L.et al 1988(5) (56.7\%) and Ljubi Ci. C.N. et al 1993(6) (59.2\%) cases cirrhosis as a cause of ascites in the age group of 30 to 40 , we also found cirrhosis in (51\%) cases as a cause of ascites.

Male to female ratio is more than one for cirrhosis as a cause of ascites. Cause of this is more consumption of alcohol in males. Mean cholesterol value in ascitic fluid in present study was found to be $21+5.96 \mathrm{mg} / \mathrm{dL}$ which resembles previous studies. In our study cholesterol levels found in ascitic fluid were between 8 and $21 \mathrm{mg} / \mathrm{dL}$ in cases of nephrotic syndrome while the value was $42 \mathrm{mg} / \mathrm{dL}$ in the only case reported by Albillos A. et al 1990 (7). Albillos A. et al 1990(7) observed cholesterol levels in ascitic fluid as 81,117 , 100 and $94 \mathrm{mg} / \mathrm{dL}$ in the four cases of CCF they studied.

We found ascitic fluid cholesterol level as $7.25 \mathrm{mg} / \mathrm{dL}$, the mean value being $16+6.72 \mathrm{mg} / \mathrm{dL}$. Albillos A. et al 1990 (7) found values of cholesterol in ascitic fluid 110 and $115 \mathrm{mg} / \mathrm{dl}$ in the two samples of tuberculous peritonitis. Sood A. et al $1995^{(8)}$ reported a mean cholesterol value of $35.07+9.72$ $\mathrm{mg} / \mathrm{dL}$ in the cases of tuberculous peritonitis. Ascitic fluid cholesterol in our study was $16-40 \mathrm{mg} / \mathrm{dL}$ with a mean value of $26+7.34 \mathrm{mg} / \mathrm{dL}$, which is in accordance with observations of Sood A. et al 1995(8). In study by Food N.C. 1956,(9) Murphy $1972^{(10)} \&$ Spieler et al 1985(11) $40 \%$ of the cases showed peritoneal metastasis. Nath et al 1966 (2) (8.57\%), Sikka et al $1967^{(4)}(7.2 \%)$ and Mehrotra et al 1972(12) (6.2\%) findings i.e. malignancy as a cause of ascites are comparable to our study (06\% cases of malignant ascites).

Although to determine malignancy in ascitic fluid cytology is very specific, but many a times the yield is very low. So in such cases the ascitic fluid cholesterol level can be tried to differentiate malignant from non - malignant ascites. Same was tried in one study by Garg R. et al 1993(13) and differentiation of tuberculous lesion from ascites in malignancy in another series by Sood A. et al 1995.(8) Garg R. et al 1993(13) used a cut off level of cholesterol levels in ascitic fluid as $48 \mathrm{mg} / \mathrm{dL}$ to draw a line between malignant and non malignant ascites. They found out it's sensitivity and specificity as $96.5 \%$ and $96.6 \%$ respectively.

Using a cut off level of $54.5 \mathrm{mg} / \mathrm{dL}$ Sood A et al 1995(9) found the specificity and sensitivity of ascitic fluid cholesterol levels in differentiating tuberculous from malignant lesions as $100 \%$ and $89.65 \%$ respectively. In our study cholesterol levels were 48 - $92 \mathrm{mg} / \mathrm{dL}$ with a mean value of $61.00+17.41$ $\mathrm{mg} / \mathrm{dL}$. Mean cholesterol in ascitic fluid was found to be 21 $\mathrm{mg} / \mathrm{dL}$ in ascites due to cirrhosis and in tuberculosis it was $26 \mathrm{mg} / \mathrm{dL}$. In ascites due to malignancy a mean ascitic fluid cholesterol level of $61 \mathrm{mg} / \mathrm{dL}$ was found. These values indicate that cholesterol levels in ascites due to malignancy are significantly higher than those found in non - malignant lesions. Moreover, it has been noted that cases positive for malignant cells had a higher ascitic fluid cholesterol (77.50 $\mathrm{mg} / \mathrm{dL})$ than those which were negative on cytology $(51.25$ $\mathrm{mg} / \mathrm{dL}$ ). Thus, in doubtful cases ascitic fluid cholesterol can help to guide us whether the smear is truly positive or not.

It is postulated that cholesterol is derived from malignant cell membrane Prieto M et al 1988.(14) Relative blocking of peritoneal lymphatic drainage may also result in 
sequestration of cholesterol macromolecule into the peritoneal cavity. Although the newer techniques like electron microscopy and immuno histochemistry bring down the false negative results on cytology, the techniques are quite complicated and more over they are not available at all centres. On the other hand ascitic fluid cholesterol level extraction is simple and cost effective method for aiding detection of malignant lesions causing ascites.

\section{CONCLUSIONS}

Statistically there is significant difference between ascitic fluid cholesterol levels in non - malignant (i.e. liver disease or tuberculosis) and malignant ascites. Thus, ascitic fluid total cholesterol concentration is helpful in differentiating malignant from non - malignant effusion. In the present study, cholesterol levels in ascitic fluid were found to be greater in smears positive/suspicious for malignant cells on cytology than those which were negative for malignant cells. So, in doubtful smears ascitic fluid cholesterol level can guide us in determining as to whether the smear is truly positive for malignant cells or not.

\section{REFERENCES}

[1] Jain SC, Misra SM, Misra NP, et al. Diagnostic value of ascitic fluid examination. J Asso Physicians India 1966;14(1):59 - 69.

[2] Nath K, Mital HS, Mishra SD, et al. Diagnostic value of ascitic fluid examination. J Assoc Physicians India 1968;16(12):991 - 6.

[3] Mehrotra MP, Mangal RP, Biochemical and cytological findings of ascitic fluid in different disorders - a preliminary report. J Assoc Physicians India 1964;12:53 61.
[4] Sikka KK, Nath K, Agarwal SN, et al. Study of serum proteins in health and in ascites of varying aetiology. J Assoc Physicians India 1967;15(12):591 - 4.

[5] Tito L, Rimola A, Gines P, et al. Recurrence of spontaneous bacterial peritonitis in cirrhosis: frequency \& predicative factors. Hepatology 1988;8(1):27 - 31.

[6] Ljubicic N, Bilic A, Babic Z, et al. The significance of low levels of total proteins, albumin, globulins and compliment factors, in ascitic fluid and the development of spontaneous bacterial peritonitis in patients with liver cirrhosis. Lijec Vjesn 1992;114(9 - 12):213 - 5.

[7] Albillos A, Ciervas - Mons V, Millan I, et al. Ascitic fluid polymorphonuclear cell count and serum to ascitic albumin gradient in the diagnosis of bacterial peritonitis. Gastroenterology 1990;98(1):134 - 40.

[8] Sood A, Garg R, Kumar R, et al. Ascitic fluid cholesterol level in malignant and tubercular ascites. J Assoc Physicians India 1995;43(11):745 - 7.

[9] Foot NC. The identification of neoplastic cells in serous effusions: critical analysis of smears from 2,029 persons. Am J Pathol 1956;32(5):961 - 77.

[10] Murphy WM, Ng AB. Determination of primary site by examination of cancer cells in body fluids. Am J Clin Pathol 1972;58(5):479 - 88.

[11] Spieler P, Gloor F. Identification of type and primary site of malignant cells by examination of exfoliated tumour cells in serous fluids. Comparison with diagnostic accuracy on small histologic biopsies. Acta Cytol 1985;29(5):753 - 67.

[12] Mehrotra MP, Saxena KK, Mathur DC. aetiological classification of ascites. Indian J Med Res 1972;60(7):1089 - 100.

[13] Garg R, Sood A, Arora S, et al. Ascitic fluid cholesterol in differential diagnosis of ascites. J Assoc Physicians India 1993;41(10):644 - 6.

[14] Prieto M, Gómez - Lechón MJ, Hoyos M, et al. Diagnosis of malignant ascites. Comparison of ascitic fibronectin, cholesterol, and serum - ascites albumin difference. Dig Dis Sci 1988:33(7):833 - 8. 